\title{
Project-Level Safety Management Framework for Semiconductor Project
}

\author{
Lan Zhang, 2, *, Thomas Zhang ${ }^{3}$, Junhui Heng ${ }^{1}$ \\ ${ }^{1}$ Century 3 (Shanghai) Inc., Shanghai, China \\ ${ }^{2}$ School of Naval Architecture, Ocean and Civil Engineering, Shanghai Jiao Tong University, Shanghai, China \\ ${ }^{3}$ Department of Economics, University of Chicago, Chicago, USA \\ Email address: \\ lan.zhang@century3inc.cn (Lan Zhang), tqzhang@uchicago.edu (Thomas Zhang), Junhui.heng@century3inc.cn (Junhui Heng) \\ ${ }^{*}$ Corresponding author
}

\section{To cite this article:}

Lan Zhang, Thomas Zhang, Junhui Heng. Project-Level Safety Management Framework for Semiconductor Project. American Journal of Civil Engineering. Vol. 9, No. 6, 2021, pp. 186-193. doi: 10.11648/j.ajce.20210906.12

Received: October 20, 2021; Accepted: November 5, 2021; Published: November 12, 2021

\begin{abstract}
Safety is one of the greatest challenges in the construction industry. Researchers proposed various safety systems to manage site safety and improve safety performance at the project level. However, these safety systems still exhibit large disconnections between the theoretical components of the systems, luck the risk prevention from specific work procedure and controlling methods. As a result, different safety teams often implement safety plans and activities in different ways, yielding different results without stability of the safety system. A safety framework that based on the construction method statement with a clear logic of safety management elements under controlling points is proposed to increase the efficiency of safety system execution at the project level to reduce the safety risks systematically. This study begins by analysing safety systems currently on the market and breaks them down to three main components: setting up the framework through systematic models, interconnecting various safety elements through safety management theories with logic, and controlling safety management data flow through an artificial neural network model, where corporate safety management frameworks are incorporated at the project level. Then the framework is further applied and tested in a semiconductor project. This framework provides an integration of safety elements, field activities and associated risks, draft the path and flow of information data generated from the safety activities and controlling points of data which enable the field safety management system to be executed with new technology of cloud based algorithm at project levels. Because each project is different based on the construction methods and sequence, the framework only covers a certain depth in the construction process based on the assumption of construction sequence presented in the study. Nevertheless, each project requires a custom design framework to accommodate the special construction method and sequence which might be different from this study to increase construction safety performance.
\end{abstract}

Keywords: Safety Systems, Safety Management, Safety Management Frameworks

\section{Introduction}

The construction industry is one of the most rapidly growing industries in China. Its annual revenue in 2020 amounted to 26394.7 billion RMB and $26.0 \%$ of China's GDP [1]. The industry has been very successful and earned China the title of fastest constructor in the world [2]. However, construction safety remains a big challenge. A total of 773 construction-related accidents and 904 construction-related deaths occurred in 2019 [3]. These accidents are tragedies for many families and result in losses for companies and society.
Construction is a complicated process which involves labour, materials, equipment, construction methods, and logistic constraints [4]. In addition, when a project is executed, even though safety performance is a priority, the schedule, quality, and cost are also important factors that should be considered. Increasing safety performance efficiency with limited resources is important.

To increase safety performance, the Chinese government agency Ministry of Housing and Urban-Rural Development of the People's Republic of China (2019) issued the national standard GB 50656 "Construction Company Safety Manage 
Criterion" to guide general contractors in safely executing projects. Figure 1 shows the standard GB 50656 safety system and the relationships between its safety elements that we call the "safety management system framework." The framework outlines the objectives (4.1), environment, health, and safety (EHS) policy (4.2), plan (4.3), execution (4.4), inspection (4.5), and assessment (4.6). This framework helps the project management team at the construction site successfully execute safety management plans (5).
However, from Figure 1, continuous improvement is an unmeasurable action. The framework is a flow diagram and does not illustrate the logic of the relationship between the elements, and there is no data flow or control of safety management information. This study will analyse these issues and provide a solution for providing a better framework that project level safety professionals can follow to increase work efficienc.

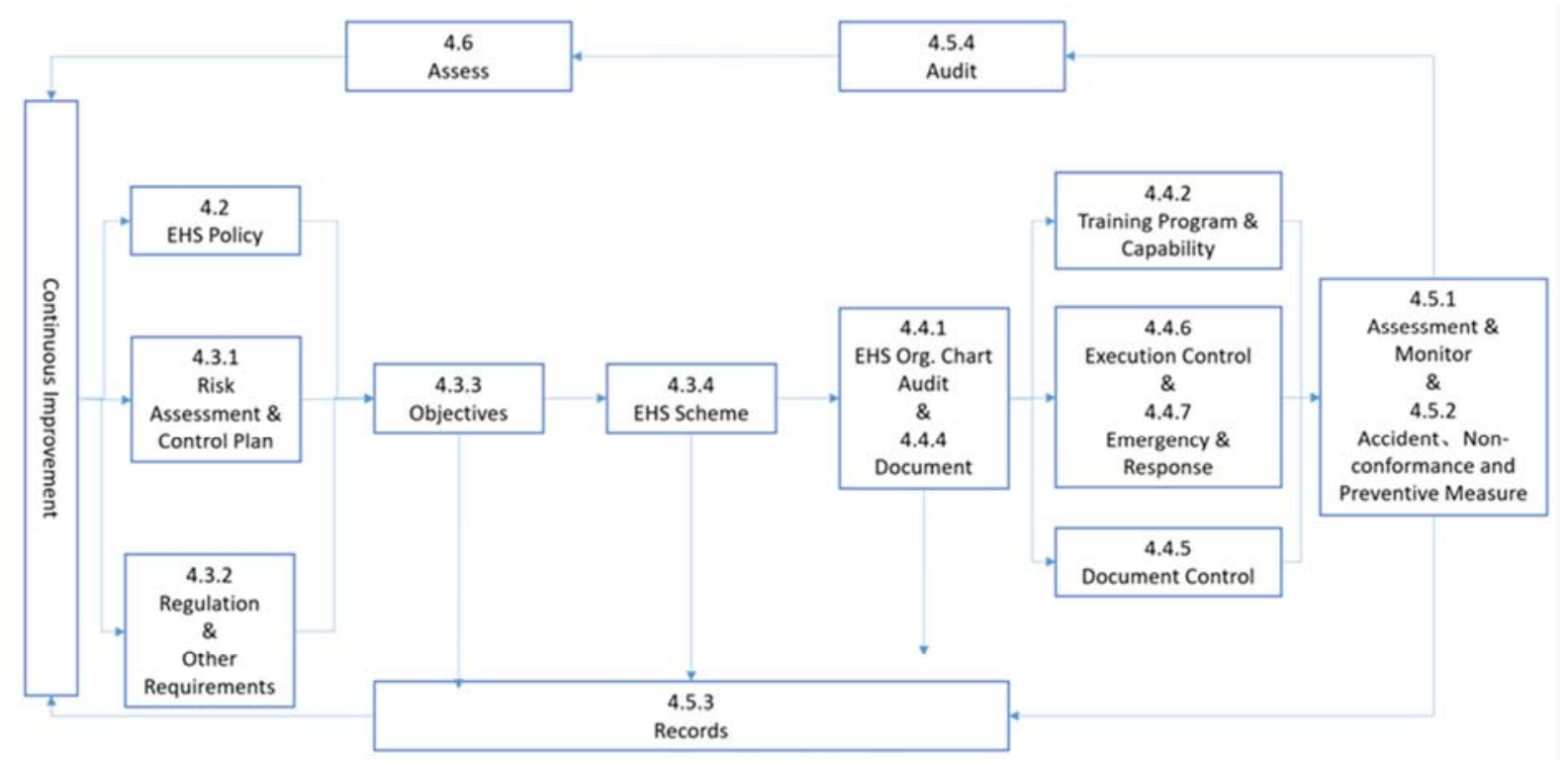

Figure 1. EHS System and relationship between GB 50656-2019 elements.

\section{Literature Review}

In addition to GB 50656-2019, many researchers have explored better frameworks to guide construction site safety to promote efficient safety management and reduce losses.

Fung et al.'s “A Stress-Strain Model for resilience engineering for construction safety and risk management" [8] provides a model to characterize and assess the 'Resilience' of the management system by monitoring the relationship of demands or challenge events and the adaptive capacity of the organization to response based on the static situation. A dynamic nature of construction site shall be born from construction sequence.

Park et. al.'s “A framework for construction safety management and visualization system" [9] integrates planning, inspection, and education modules with internet of things (IOT) technology visualisation. However, the study did not address the safety procedure and the internal logic of the safety elements, which did not connect elements effectively.

Robelski et al.'s “ICT-Enable Mobile Work: Challenges and Opportunities for Occupational Health and Safety System" [10] addresses safety management tools and legal issues but does not have a clear safety management structure.

Jin et. al.'s "The Construction of Builder Safety
Supervision System Based on CPS" [11] provides a monitoring schematic diagram and an early warning system that enables the safety management team to take actions before an accident takes occurs.

Khan et. al.'s "Occupational health and safety in construction industry in Pakistan using modified "SIRA model" [12] identifies the causes and consequences of critical hazards on a construction site without specifying safety procedures and evaluations.

Agumba et. al.'s "Health and Safety Management Practices in Small and Medium Enterprises in the South African Construction Industry" [13] concludes that the commitment of upper management is very important but does not discuss a safety framework.

Yiu et. al.'s “Implementation of Safety Management System for Improving Construction Safety Performance: A Structural Equation Modelling Approach" [14] identifies measurable safety outcomes through inspection. However, the study did not sufficiently describe the safety system and its working mechanism.

A summary of current studies is outlined in Table 1.

The study objectives are to turn project site safety management issues into research issues, use current market methods to resolve these issues and form a safety management framework. 
Table 1. Previous studies on safety management systems: contributions and limitations.

\begin{tabular}{|c|c|c|c|c|}
\hline Reference & First author & Title & Contribution & Issues not resolved \\
\hline 8 & $\begin{array}{l}\text { Ivan W. H. } \\
\text { Fung }\end{array}$ & $\begin{array}{l}\text { A Stress-strain Model for resilience engineering } \\
\text { for construction safety and risk management }\end{array}$ & $\begin{array}{l}\text { Characterize and ass the Resilience of } \\
\text { management system and adaptive capacity } \\
\text { to response }\end{array}$ & Static assumptions \\
\hline 9 & C.-S. Park & $\begin{array}{l}\text { A framework for construction safety management } \\
\text { and visualization system }\end{array}$ & $\begin{array}{l}\text { Planning, inspection, and education } \\
\text { modules and visualization engineering }\end{array}$ & $\begin{array}{l}\text { Safety procedures and elements } \\
\text { are not fully addressed. }\end{array}$ \\
\hline 10 & S Robelski & $\begin{array}{l}\text { ICT-Enabled Mobile Work: Challenges and } \\
\text { Opportunities for Occupational Health and } \\
\text { Safety Systems }\end{array}$ & $\begin{array}{l}\text { Removes operational health risks and } \\
\text { addresses safety management tools and } \\
\text { legal issues. }\end{array}$ & $\begin{array}{l}\text { The content and structure of the } \\
\text { occupational health and safety } \\
\text { system content are not given. }\end{array}$ \\
\hline 11 & Wei Jin & $\begin{array}{l}\text { The Construction of Builder Safety Supervision } \\
\text { System Based on CPS }\end{array}$ & $\begin{array}{l}\text { Gives a schematic diagram of a monitoring } \\
\text { and early warning system. }\end{array}$ & $\begin{array}{l}\text { Did not address safety system } \\
\text { elements and their relationships. }\end{array}$ \\
\hline 12 & Khan & $\begin{array}{l}\text { Occupational health and safety in construction } \\
\text { industry in Pakistan using modified-SIRA method }\end{array}$ & $\begin{array}{l}\text { Identifies the causes of critical hazards and } \\
\text { their consequences. }\end{array}$ & $\begin{array}{l}\text { Did not address execution and } \\
\text { emergencies and responses. }\end{array}$ \\
\hline 13 & Agumba & $\begin{array}{l}\text { Health and Safety Management Practices in } \\
\text { Small and Medium Enterprises in the South } \\
\text { African Construction Industry }\end{array}$ & $\begin{array}{l}\text { Concluded that upper management } \\
\text { commitment and involvement in EHS is } \\
\text { important. }\end{array}$ & $\begin{array}{l}\text { Did not address a plan, execution, } \\
\text { and evaluation. }\end{array}$ \\
\hline 14 & Yiu & $\begin{array}{l}\text { Implementation of Safety Management System } \\
\text { for Improving Construction Safety Performance: } \\
\text { A Structural Equation Modelling Approach }\end{array}$ & Identifies measurable safety outcomes. & $\begin{array}{l}\text { Did not elaborate how the system } \\
\text { operates. }\end{array}$ \\
\hline
\end{tabular}

\section{Methodology}

The study starts from the facts that the construction safety is under performed to conclude that the current safety management system which supports the safety performance needed to be improved (1.0).

By reviewing the current safety system, major theories and researches to identify the limitations and focus on the research questions (2.0).

With the reference of system model from PMBOK, set-up the framework by three subsystems i.e. inputs, construction sequence and outputs. Run the system by PDCA model (3.1). Also, by utilizing the management principles, based on the safety guidelines, analyse the scope of the work, align the objectives, identify the risks to achieve the targets, plan the mitigations of the risks within the execution plan and check at daily construction permit sign-off (3.2). Using the artificial network model to draft the data flow that generated from each safety activities and element with controlling points of signing off the daily work permit and issuing none compliance report (NCR) (3.3).

Based on the above theories to form the construction safety management system framework (4.0), followed by a case study to further demonstrate the application of the framework and validate the framework (5.0). At the last, the conclusion and research limitation are presented (6.0). The methodology is shown in Figure 2.

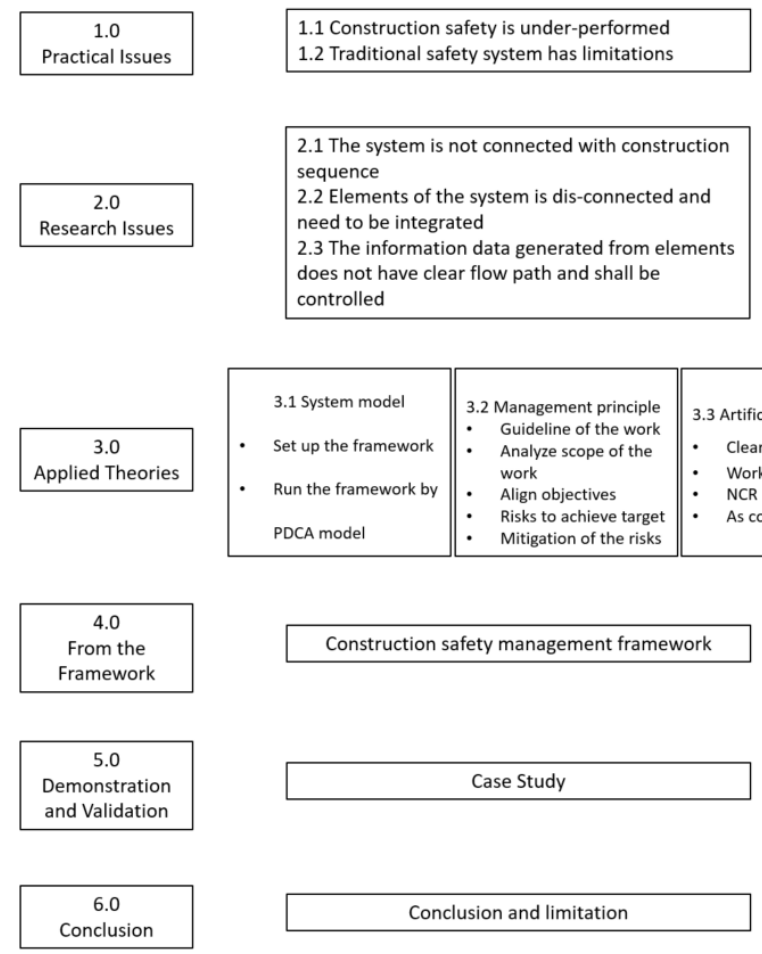

Figure 2. Methodology for constructing a Project Level Safety Management System Framework. 


\section{Framework Model}

The PMBOK system model (Figure 3) has four elements: inputs, phases, project management outputs, and project deliverables. The inputs are the information entered into the phases, where the phases are the project timeline with activities. Outputs are the results of the activities, and the deliverables are the system's final products.

Based on the system model, the first layer of the proposed safety framework has the input, phases, output, and gateways as shown in Figure 4. The inputs are all the information and activities before execution, while the phases are the project execution stages. The output is the analysis and assessment of the execution of the safety management plan. The gateways are the control points where data flow and are stopped and released after being analysed, processed, and controlled.

For the inputs, it is logical to use regulations, client requirements, standard procedures, and other guidelines as the basic foundation and baseline to guide safety management activities. Then, as per the construction process from the phases, specify the scope of the project, set clear safety targets, and by using risk assessment theory determine the highest risk of the safety management plan. Next, assess the risk and draft a work plan. Finally, develop a work permit and review and discuss it with the crews going to the construction site, and then post it at the job site every day for safety inspection. For the phases, the first layer is preparation, construction, and handover.

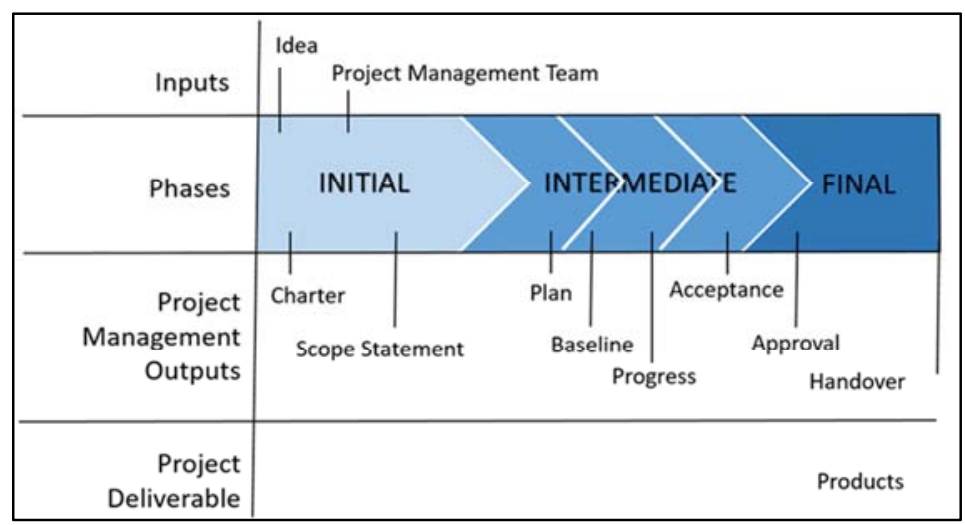

Figure 3. $P M B O K$ system model.

In the case study, the construction element will be further detailed for underground; structure and building; and mechanical, electrical, and plumbing (MEP) constructions and testing and commissioning (T\&C).

At the output, after the safety team performs site inspection, a no-compliance report (NCR) specifies all violations, risks, and improvements needed to keep the site safe. The NCR is the basic information used to evaluate safety performance, whereas the NCR close rate improves the team's safety performance. Based on the NCR and NCR close rate data, various reports can be made for the different on-site stakeholders to report their actions and focus areas.

Artificial neural network models (1, 2, and 3) demonstrate how data flow, meet and are controlled and distributed. The models can be utilised to control safety management information as per Figure 4.

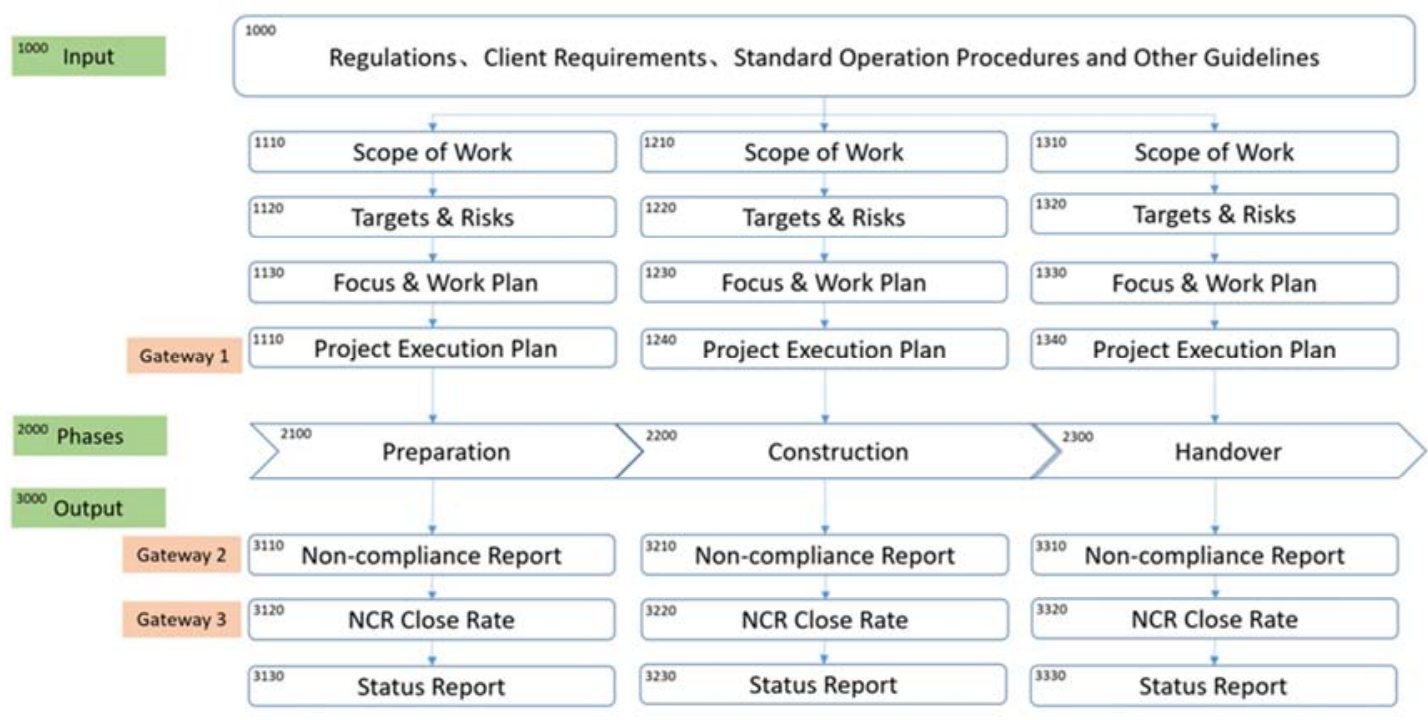

Figure 4. Project level safety management system framework. 


\section{Case Study}

As an introduction, a project brief was given and the client's requirements were presented followed by the implementation of safety management plans. The construction phase of the framework was further detailed into underground, structure and building, MEP, and T\&C sub-phases to demonstrate how the framework guides site safety management. In this project site, a cloud-based safety management software was developed based on the proposed framework, in which all management teams worked on one platform to process information; the final results of key safety indicators were presented to validate the efficient functioning of the safety management system.

\subsection{Project Description}

Project A is located at the Chengdu campus of Chengdu, including a new four-story assembly and text (AT) building and modifications to existing utility buildings and systems to support the new AT facility. The total built area is $55,484 \mathrm{~m}^{2}$, including the following buildings:

1) Site modifications (new parking, road, underground and above-ground utility, and pipe racks).

2) CDAT2: A new 4-story concrete AT facility with a total built area of $50,484 \mathrm{~m}^{2}$.

3) Existing Building renovations:

a) Clean bridge to connect the new AT facility to an existing AT facility.

b) Canteen and kitchen renovations and office building security control room modifications.

c) Addition of a data centre in the existing Fab.

d) Existing pipe rack modification.

e) Addition of a new ultra-pure water (UPW) in existing utility buildings.

f) Existing chiller modification.

g) Addition of a new waste water system in existing utility buildings.

h) Forming-gas station modification.

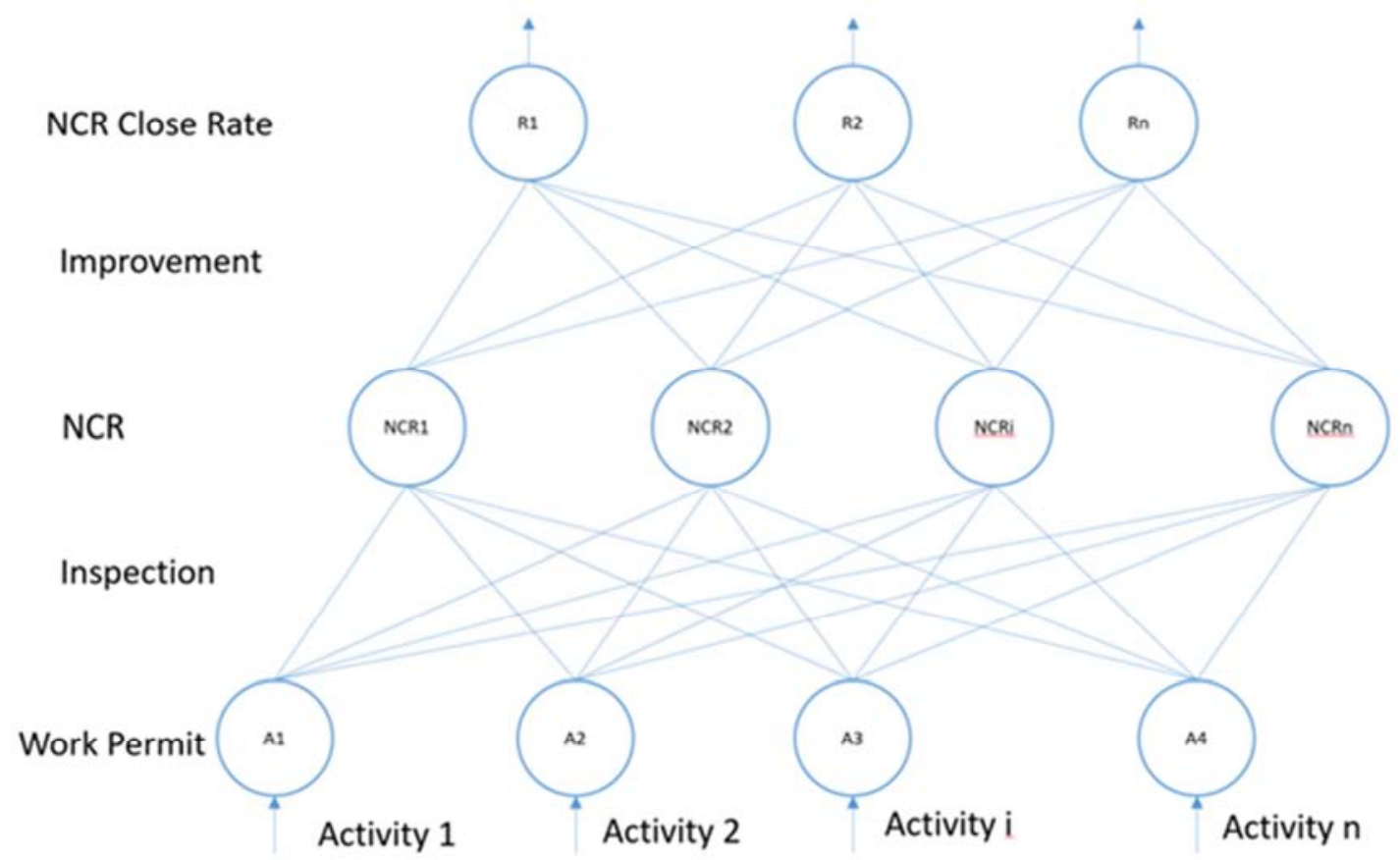

Figure 5. Data flow path based on an artificial neural network model.

\subsection{Safety Management Framework}

During construction, the project is further developed into four phases: underground (2210), structure and building (2220), MEP (2230), and T\&C (2240) because of the nature of construction and activities in different environments.

For the input, based on government regulations, including GB 50656-2019, client's safety requirements, and CENTURY 3 standard safety operation procedures, the team analysed the major activities $(1211,1221,1231,1241)$ and possible safety risks $(1211,1222,1232,1242)$ and drafted a work plan by taking measures to control the risks (1231, $1232,1233,1243)$. These measures are incorporated into the daily work permit when the safety management team explains, discusses, and instructs on-site labour before construction begins.

During inspection, the safety and construction teams walk through the site and talk to the labourers to correct minor safety violations while simultaneously recording safety violations (NCR) that cannot be corrected instantly on site; these are then discussed with the contractor's higher management, and resources that improve site safety are requested. The NCR is a useful tool for assessing and controlling safety on-site and a communication tool for stakeholders among contractors.

The framework is presented in Figure 6. 


1000 Input

Figure 6. Case study project level safety management system framework.

\subsection{Work Permit, NCR, NCR Close Rate}

Work permit is a good tool for identifying hazards, strengthening the communication between site workers and project supervisors/safety teams, which enable the site crews to be aware, safe and right in their approach to getting their jobs done. Therefore, we use the work permit as a control point that the work permit is a mandatory required and must be signed off before implementing the related work activity every day. As per the safety management system framework mentioned above (Figure 7), work permits will be used as the first gateway to analyze and mitigate the related safety hazards at each construction phase.

For the NCR, Non-compliance report is the second gateway to record the site safety findings which don't comply with the safety control measures as described in the approved work permits. The NCR includes the location and date of the violation, types of the violation and expected correction needed at certain time and actual completion date, etc. NCR is similar as the Safety Issues Tracking Log, which can be used to formalize various safety reports such as Safety Issues Category Index, Safety Issues Trending Index, and NCR Tracking Indicator, etc. NCR is the output of the safety management system, which not only provide us the visual result of the site safety situation, but also benefit the project management team to properly evaluate the site safety performance and timely adjust the safety management strategy.

Based on the NCR number, the team tracked the NCR closing rate as a major performance indicator for the status and trend of safety management as shown in Figure 7.

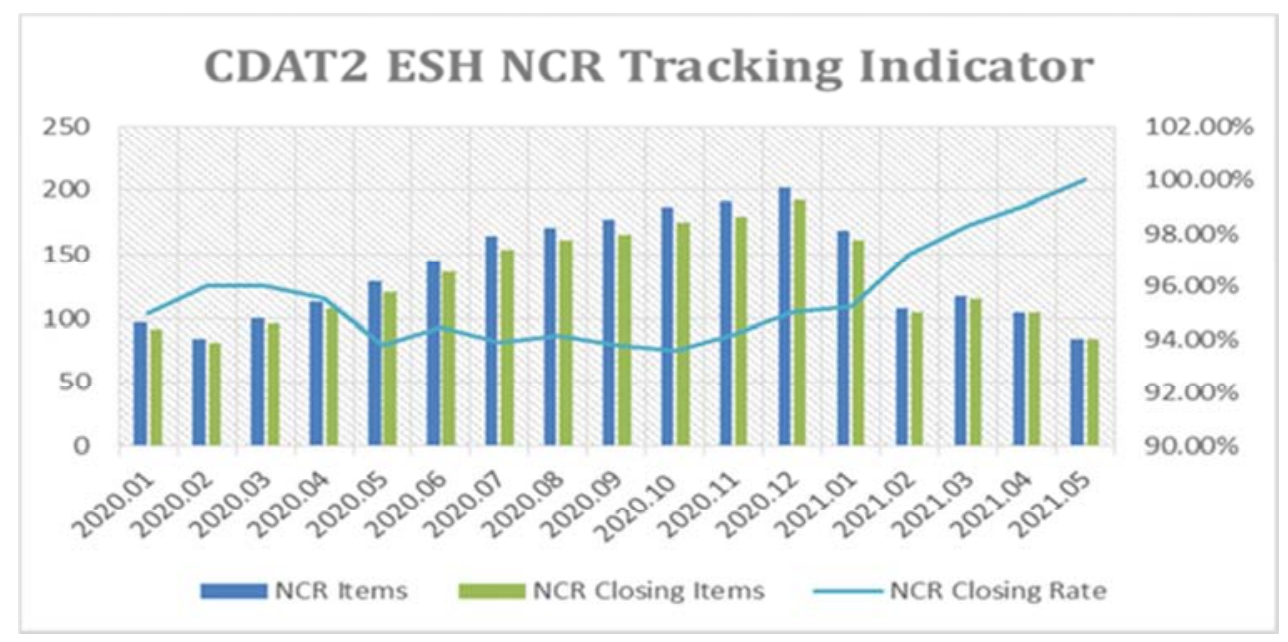

Figure 7. NCR closing rate. 


\subsection{Safety Indicator}

With the framework application in the project, table 2 present the comparison between traditional safety systems and the contribution from this safety management framework.

Table 2. Comparison between traditional safety system vs safety management framework.

\begin{tabular}{lll}
\hline No. & The characteristics of traditional safety management system & Contributions from the new safety management framework \\
\hline 1 & $\begin{array}{l}\text { Provide the related safety control plan only based on the risk categories } \\
\text { Various units or SOP are all combined into the safety management system, but } \\
\text { keep independent from each other }\end{array}$ & $\begin{array}{l}\text { Clearly outline the related elements of the safety management system } \\
\text { Keep the elements logically linked as artificial neural network to } \\
\text { achieve the continuous improvement of safety index }\end{array}$ \\
3 & $\begin{array}{l}\text { No clear safety tools are addressed to drive the safety system, lacking of } \\
\text { guideline }\end{array}$ & $\begin{array}{l}\text { Define the specific gateways to effectively implement the safety } \\
\text { system }\end{array}$ \\
4 & $\begin{array}{l}\text { Focus on the risk itself but not linked to the dynamic construction process, } \\
\text { Kacking of corresponding risk control plan }\end{array}$ & $\begin{array}{l}\text { Keep risk control same pace with the construction process at each } \\
\text { phase as a dynamic management method }\end{array}$ \\
\hline
\end{tabular}

By using a safety management system based on the framework, the project team achieved 3.1 million safety man-hours with zero recordable, five near-miss, and four first-aid cases as shown in Figure 8.

CDAT2 ESH KPI-1

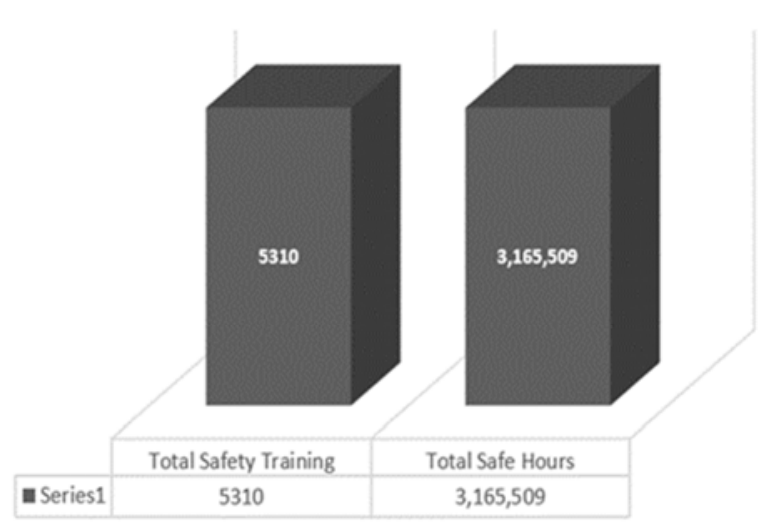

The client also gave the contractor an "Outstanding Safety Contractor" award and the project also won the "Fu Rong Cup" (award from the Sichuan province for best quality).

Figure 8. Safety performance indicator for the case study project.

\section{Conclusion}

In order to improve the safety performance in the construction industry, a safety system is the key assurance. At this study, the GB 50656 safety management framework at is analysed as a basic model. Its limitations are identified with three research questions: the connection of the framework with the construction process, the logic of the relationship between the sub-system's elements, and the controlling of management work as a whole process. In addition, the literature review presented major safety systems with their pros and cons. Based on the methodology adopted in this study, the PMBOK system model was used to set up a framework structure, major safety theory was used to connect the subsystems of the safety system, and an artificial neural network model was used to control the system's safety work and data. Furthermore, a case study is presented to demonstrate the application of this framework. From the above, we can conclude the following:

1) The project-level construction safety management framework considers the construction process where the specific risks from the construction activities can be identified and focus can be draw based on-site scenarios where the traditional safety system does not provide safety site risk specific scenarios which might result the planning work lost focus.

2) The framework connects safety management elements with a logic: treat the governments regulations, client's safety requirement and company standard operation procedures as input, review the construction activities and identify the safety risks, prioritize the risks and plan accordingly, inspect the safety activities on site and follow up with Non-compliance report to manage the safety work.

3) The framework uses work permits to control the site enable everyone on the construction site is properly trained, award the risk, has right of personal protection equipment, understand the properly work behaviour and know the measurement of evacuation. Also, the non-compliance report can evaluate the safety performance while the non-compliance close rate can further demonstrate the efficiency of the safety performance. 


\section{Limitation}

In this study, the depth of the construction phase is limited. Due to using different construction methods, every project is different which results in different risks that require different measures to control. For example, at the structure construction, reinforce concrete vs structure steel construction is different and the risk associated is different and the methodology of safety measurement shall be different. The proposed framework is still in the prototype stage. Each project must develop its own framework that is more specific and meets its own project requirements.

\section{Acknowledgements}

We would like to thank Wei Wang, Phil Hong, Weichang Shi, and Jianfan Chen for their contributions and help and Editage for editing the paper.

\section{References}

[1] National Statistics Bureau of China. "National Data". data .stats.gov.cn. Retrieved 2021-06-11.

[2] D. Hebb, The Organization of Behavior, Wiley, New York, 1949.

[3] Ministry of Housing and Urban-Rural Development of the People's Republic of China. "The General Office of the Ministry of Housing and Urban-Rural Development on 2019: Notification of production safety accidents in housing and municipal engineering." mohurd.gov.cn. 2020.

[4] Brockmann, C., Kähkönen, K., 2012, Evaluating construction project complexity, CIB Joint International Symposium, 2012.

[5] Alan Griffith, Paul Stephenson \& Khalid Bhutto., 2014, An Integrated Management System for Construction Quality, Safety and Environment: A Framework for IMS, International Journal of Construction Management. DOI: 10.080/15623599.2005.10773074.
[6] Rafiq Choudhry, Dongping Fang \& Steve Rowlinson., 2014, Challenging and Enforcing Safety Management in Developing Countries: A Strategy, International Journal of Construction Management. DOI: 10.1080/15623599.2008.10773110.

[7] Saikat Maiti \& Jae-ho Choi., 2019, An evidence-based approach to health and safety management in megaprojects., International Journal of Construction Management. DOI: 10.1080/15623599.2019.1602580.

[8] Ivan Fung, Vivian W. Y. Tam, John Chu \& Khoa Le., 2020, A Stress-Strain Model for resilience engineering for construction safety and risk management., Internationalb Journal of Construction Management. OI: 10.1080/15623599.2020.1783602.

[9] Prak, C. S., Kim, H. J., 2013, A framework for construction safety management and visualization system, Automation in Construction., 33, 95-103. https://doi.org/10.1016/j.autcon.2012.09.012.

[10] S Robelski, S Sommer, 2020, ICT-Enabled Mobile Work: Challenges and Opportunities for Occupational Health and Safety Systems, International Journal of Environmental Research and Public Health, 17 (7498). DOI: 10.3390/ijerph17207498.

[11] Jin, W., Liu, Y., Jin, Y., Jia, M., Xue, L., 2020, The Construction of Builder Safety Supervision System Based on CPS, Hindawi, 2020. https://doi.org/10.1155/2020/8856831.

[12] Khan, M. W., Ali, Y., Felice, F., Petrillo, A., Occupational Health and Safety in Construction Industry in Pakistan Using Modified-SIRA Method, 2019, Safety Science, 118, 109-118. https://doi.org/10.1016/j.ssci.2019.05.001.

[13] Agumba, J. N., Haupt, T., Pretorius, J. H., 2013, Health and Safety Management Practices in Small and Medium Enterprises in the South African Construction Industry, ASOCSA 7th Built Environment Conference.

[14] Nicole S. N. Yiu, Daniel W. M. Chan, N. N. Sze, Ming Shan and Albert P. C. Chan, "Implementation of Safety Management System for Improving Construction Safety Performance: A Structural Equation Modelling Approach", Buildings, 2019, Volume 9, https://www.mdpi.com/2075-5309/9/4/89. 